\title{
Vitamin D status among infants, children, and adolescents in southeastern China*
}

\author{
Ling-li WANG ${ }^{1}$, Hui-yan $\mathrm{WANG}^{1}$, Huai-kai $\mathrm{WEN}^{1}$, Hong-qun TAO ${ }^{1}$, Xiao-wei ZHAO ${ }^{\dagger \neq 2}$ \\ ( ${ }^{1}$ Unit of Laboratory Medicine, Second Hospital Affiliated to Wenzhou Medical University, Wenzhou 325027, China) \\ $\left({ }^{2}\right.$ College of Life and Environmental Science, Wenzhou University, Wenzhou 325035, China) \\ †E-mail: sherwood@wzu.edu.cn \\ Received Nov. 19, 2015; Revision accepted Mar. 8, 2016; Crosschecked June 18, 2016
}

\begin{abstract}
Objective: Vitamin D deficiency and insufficiency are global public health problems, which must first be identified before they can be appropriately addressed, and yet information is strikingly lacking in most parts of the Asia and Pacific region. The study aimed to document and account for the actual situation in Wenzhou on the southeastern coast of China. Subjects and methods: Serum 25-hydroxyvitamin D levels among a total of 5845 infants, preschool children, school children, and adolescents aged 1-18 years were examined between March 2014 and February 2015. Results: Their mean levels were (110.2 \pm 26.8$)$, (77.5 \pm 25.7$),(55.6 \pm 15.4)$, and $(47.2 \pm 13.9) \mathrm{nmol} / \mathrm{L}$, respectively. Older age groups were involved in increasing risk of vitamin $D$ deficiency and insufficiency. There were significant seasonal differences in its median level and prevalence of deficiency and insufficiency among school children and adolescents, but there was no significant sex difference in mean level and prevalence in any age group. Conclusions: Vitamin D deficiency and insufficiency were prevalent among infants, preschool children, school children, and adolescents in Wenzhou. A vitamin D-rich diet and outdoor activities for 1-2 h per day under the natural conditions favorable to its endogeous synthesis do not suffice. The vitamin D status in Wenzhounese infants excelling over that in the US was the result of its supplementation thanks to the Chinese Medical Association recommendations, which should be consequently extended to more age groups. Life style shaped by socio-economic environments affects vitamin D status. Knowledge on the importance of vitamin $D$ for healthy growth should be popularized.
\end{abstract}

Key words: Vitamin D, Deficiency, Child, China http://dx.doi.org/10.1631/jzus.B1500285

\section{Introduction}

Increasing evidence suggests that vitamin D has multiple biological functions in addition to the classical effects on calcium and phosphorus metabolism and on bone health and muscle strength. Vitamin D deficiency and insufficiency have been associated with non-skeletal diseases, such as depression, diabetes, heart failure, high blood pressure, rheumatoid

\footnotetext{
${ }^{\ddagger}$ Corresponding author

* Project supported by the Wenzhou Municipal Science and Technology Bureau Grant (No. Y20150313), China

(D) ORCID: Xiao-wei ZHAO, http://orcid.org/0000-0003-3315-3866

(C) Zhejiang University and Springer-Verlag Berlin Heidelberg 2016
}

CLC number: R591.44

arthritis, selected cancers, schizophrenia, and tuberculosis (Zittermann and Gummert, 2010; Schöttker et al., 2013). Although there is no consensus on the optimal vitamin D status, most specialists agree that its deficiency should be defined as serum 25-hydroxyvitamin D (25-OHD) levels at less than $50 \mathrm{nmol} / \mathrm{L}$, insufficiency as levels between 50 and $75 \mathrm{nmol} / \mathrm{L}$, and adequacy as levels at more than $75 \mathrm{nmol} / \mathrm{L}$ (Holick et al., 2011). The levels even higher than 100 or $150 \mathrm{nmol} / \mathrm{L}$ have been recommended based on epidemiologic data (Bischoff-Ferrari et al., 2006).

Vitamin D status in an individual is dependent on genetic inheritance, lifestyle, and geographical conditions. Systematic reviews revealed that vitamin 
D deficiency and insufficiency are prevalent in all ethnicities and age groups where data are available around the globe, even in those living in areas with low latitude where a high level of solar ultraviolet B radiation initiates significant photochemical synthesis of vitamin $\mathrm{D}$ in human skin and those residing in advanced countries where vitamin D fortification has now been implemented for years (Wahl et al., 2012; Palacios and Gonzalez, 2014). For example, $72 \%$ of school children aged 7-12 years in Kuala Lumpur, Malaysia had serum 25-OHD levels indicative of vitamin D deficiency (Khor et al., 2011). Results from the US National Health and Nutrition Examination Survey indicated that prevalence of vitamin D deficiency or insufficiency in the 12- to 15-year-old US population was $31 \%$ or $79 \%$, respectively (Ganji et al. 2012). The situation is, however, still uncertain because information on 25-OHD levels, especially among infants, children, and adolescents, is strikingly lacking in various parts of the world including most of the Asia and Pacific region (Wahl et al., 2012; Palacios and Gonzalez, 2014).

Wenzhou, literally meaning "temperate prefecture" in Chinese, is an affluent district on the southeastern coast of China at latitude $28^{\circ} \mathrm{N}$ and its diet is full of sea fish, such as cod, herring, and mackerel. The question arises of what is the case in such a place which is provided with plenty of solar radiation and abounds in foodstuffs containing substantial amounts of vitamin D? The aim of this study was to document and account for the actual situation of healthy infants, children, and adolescents living in a middle subtropical region where the natural conditions for cutaneous synthesis of vitamin D appear favorable and its dietary intake seems ample.

\section{Subjects and methods}

\subsection{Subjects and study design}

Subjects in this cross-sectional study were recruited from healthy clients no more than 18 years old who visited the Second Hospital (also named the Yuying Children's Hospital) Affiliated to Wenzhou Medical University (China) for health examination between March 2014 and February 2015. They were proved in the examination to have no evidence of abnormal liver or renal function or other diagnosed medical conditions that might potentially interfere with vitamin D metabolism, and agreed to take part in the study and provided informed consent signed by themselves or their legal guardians after the purpose and detailed design of the study were explained to them. A total of 5845 eligible subjects were divided into 4 groups based on their ages: $0-12$ months, 26 years, 7-11 years, and 12-18 years, representing infancy, preschool childhood, school childhood, and adolescence, respectively. February through April was astronomically specified as spring, May through July as summer, August through October as fall, and November through January as winter. The age, sex and seasonal distributions are listed in Table 1. The study was approved by the Human Research Ethics Committee at our hospital and was in accordance with the principles laid down in the World Medical Association Declaration of Helsinki.

Table 1 Age, sex, and seasonal distributions of subjects

\begin{tabular}{lrrrrr}
\hline \multirow{2}{*}{ Group } & \multicolumn{5}{c}{ Seasonal distribution } \\
\cline { 2 - 6 } & Spring & Summer & Fall & Winter & Total \\
\hline Infant & 69 & 211 & 216 & 131 & 627 \\
Boy & 48 & 133 & 131 & 60 & 372 \\
Girl & 21 & 78 & 85 & 71 & 255 \\
Preschool child & 325 & 772 & 675 & 508 & 2280 \\
Boy & 223 & 514 & 440 & 300 & 1477 \\
Girl & 102 & 258 & 235 & 208 & 803 \\
School child & 220 & 778 & 794 & 293 & 2085 \\
Boy & 151 & 539 & 547 & 195 & 1432 \\
Girl & 69 & 239 & 247 & 98 & 653 \\
Adolescent & 110 & 352 & 275 & 116 & 853 \\
Boy & 84 & 267 & 191 & 87 & 629 \\
Girl & 26 & 85 & 84 & 29 & 224 \\
\hline Total & 724 & 2113 & 1960 & 1048 & 5845 \\
\hline
\end{tabular}

Height and weight were measured to the nearest $0.1 \mathrm{~cm}$ and $0.1 \mathrm{~kg}$, respectively, with each subject clad only in light clothing. A questionnaire (Liu et al., 2003) based on the 7-d recall (Sallis et al., 1993) was used to assess subjects' outdoor activities. They and/or their legal guardians were asked to recall the hours engaging in outdoor activities over the past week, and then average outdoor activity time per day was calculated. Dietary vitamin D intake was assessed using the 24-h dietary recall (Lytle et al., 1993). The food items consumed during the past $24 \mathrm{~h}$ were reported by subjects and/or their legal guardians for $3 \mathrm{~d}$ consecutively ( 2 weekdays and Saturday or Sunday) including breakfast, lunch, supper, and betweenmeal snacks. Average dietary vitamin D intake per 
day was calculated using the Nutrition Calculator Version 2.65 (Chinese Center for Disease Control, Beijing, China). According to the above described definition, serum 25-OHD levels less than $50 \mathrm{nmol} / \mathrm{L}$ were classified as vitamin $\mathrm{D}$ deficiency, levels between 50 and $75 \mathrm{nmol} / \mathrm{L}$ as insufficiency, and levels more than $75 \mathrm{nmol} / \mathrm{L}$ as adequacy.

\subsection{Vitamin D measurement}

Venous samples were collected in the morning after an overnight fast except for infants. The level of 25-OHD was determined with an electrochemiluminescence binding assay on a Cobas e 601 Analyzer (Roche Diagnostics GmbH, Mannheim, Germany), whose intra- and inter-assay coefficients of variation were within $4 \%$ and $10 \%$, respectively. A matched test kit was used, following the manufacturer's procedure.

\subsection{Statistical analyses}

Measurement results were expressed as mean \pm standard deviation (SD) or median (quartile range) depending on the data distribution. The KolmogorovSmirnov test was applied to determine if a dataset was normally distributed and the Levene test was used to determine if relevant datasets had equal variances. Accordingly, the Student's $t$-test, Cochran-Cox test, chi-square test, Mann-Whitney $U$-test, Kruskal-Wallis $H$-test, or Nemenyi test was performed to compare serum 25-OHD levels, vitamin D statuses, dietary vitamin D intakes, and outdoor activity time. Significance was set at $P<0.05$ except in the KolmogorovSmirnov and Levene tests, where the significance level was set at $P<0.10$.

\section{Results}

Statistical description and inference of the results from vitamin D measurement are listed in Tables 2 and 3. The mean serum 25-OHD level decreased while the decrement lessened as age increased. Accordingly, the vitamin D deficiency and insufficiency became prevalent as children grew up. Nearly $40 \%$ of school children and over $50 \%$ of adolescents were vitamin $\mathrm{D}$ deficient, while vitamin D insufficiency occurred in more than 1 of every 3 preschool children, 2 school children, and 3 adolescents, respectively. Few adolescents had vitamin D adequacy. Only $50 \%$ of preschool children exceeded the threshold of $75 \mathrm{nmol} / \mathrm{L}$. There was no significant difference in mean serum 25-OHD level or prevalence of vitamin $\mathrm{D}$ deficiency or insufficiency between boys and girls in any age group. Nor was there significant seasonal difference in median level or prevalence among infants and preschool children. For school children and adolescents, however, there were significant seasonal differences around the year, which were found only between spring and summer and between fall and winter.

Physical characteristics and vitamin D intakes of subjects are listed in Table 4. Season had an effect on the outdoor activity time in any age group. The time in summer/fall was significantly longer than that in spring/winter, but season had no effect on the dietary vitamin D intake in any age group (data not shown). The much higher median intake for infants than for the other three age groups was due to vitamin D supplementation in accordance with the Chinese

Table 2 Mean serum 25-OHD levels and vitamin D statuses among infants, children, and adolescents, and their sex differences

\begin{tabular}{|c|c|c|c|c|c|c|c|c|}
\hline \multirow{3}{*}{ Group } & \multicolumn{2}{|c|}{ 25-OHD (nmol/L) } & \multicolumn{6}{|c|}{ Vitamin D status (\%) } \\
\hline & \multirow{2}{*}{ Mean \pm SD } & \multirow{2}{*}{$P$} & \multicolumn{2}{|l|}{ Deficiency } & \multicolumn{2}{|c|}{ Insufficiency } & \multicolumn{2}{|l|}{ Adequacy } \\
\hline & & & Median $(95 \% \mathrm{CI})$ & $P$ & Median $(95 \% \mathrm{CI})$ & $P$ & Median $(95 \% \mathrm{CI})$ & $P$ \\
\hline Infant & $110.2 \pm 26.8$ & 0.772 & $1.4(0.5-2.3)$ & 0.366 & $8.6(6.4-10.8)$ & 0.897 & $90.0(87.7-92.3)$ & 0.681 \\
\hline Boy & $110.4 \pm 25.9$ & & $1.1(0.0-2.2)$ & & $8.6(5.8-11.4)$ & & $90.3(87.3-93.3)$ & \\
\hline Girl & $109.8 \pm 27.9$ & & $2.0(0.3-3.7)$ & & $8.6(5.2-12.0)$ & & $89.4(85.6-93.2)$ & \\
\hline Preschool child & $77.5 \pm 25.7$ & 0.232 & $15.1(13.6-16.6)$ & 0.384 & $34.5(32.5-36.5)$ & 0.894 & $50.4(48.3-52.5)$ & 0.518 \\
\hline Boy & $76.7 \pm 26.4$ & & $15.6(13.7-17.5)$ & & $34.5(32.1-36.9)$ & & $49.9(47.4-52.4)$ & \\
\hline Girl & $78.9 \pm 26.6$ & & $14.2(11.8-16.6)$ & & $34.5(31.2-37.8)$ & & $51.3(47.8-54.8)$ & \\
\hline School child & $55.6 \pm 15.4$ & 0.196 & $38.1(36.0-40.2)$ & 0.142 & $51.6(49.5-53.7)$ & 0.225 & $10.3(9.0-11.6)$ & 0.687 \\
\hline Boy & $56.7 \pm 15.7$ & & $37.0(34.5-39.5)$ & & $52.5(49.9-55.1)$ & & $10.5(8.9-12.1)$ & \\
\hline Girl & $53.3 \pm 15.6$ & & $40.4(36.6-44.2)$ & & $49.6(45.8-53.4)$ & & $10.0(7.7-12.3)$ & \\
\hline Adolescent & $47.2 \pm 13.9$ & 0.213 & $54.6(51.3-57.9)$ & 0.259 & $38.9(35.6-42.2)$ & 0.062 & $6.5(4.8-8.2)$ & 0.165 \\
\hline Boy & $48.7 \pm 13.9$ & & $55.8(51.9-59.7)$ & & $37.0(33.2-40.8)$ & & $7.2(5.2-9.2)$ & \\
\hline Girl & $42.8 \pm 13.1$ & & $51.3(44.8-57.8)$ & & $44.2(37.7-50.7)$ & & $4.5(1.8-7.2)$ & \\
\hline
\end{tabular}

Data are expressed as mean \pm standard deviation (SD) or median (95\% confidence interval (CI)). 25-OHD: 25-hydroxyvitamin D 
Table 3 Median serum 25-OHD levels and vitamin D statuses among infants, children, and adolescents, and their seasonal differences

\begin{tabular}{|c|c|c|c|c|c|c|c|c|}
\hline \multirow{3}{*}{ Group } & \multicolumn{2}{|c|}{ 25-OHD (nmol/L) } & \multicolumn{6}{|c|}{ Vitamin D status (\%) } \\
\hline & \multirow{2}{*}{ Median (QR) } & \multirow{2}{*}{$P$} & \multicolumn{2}{|l|}{ Deficiency } & \multicolumn{2}{|l|}{ Insufficiency } & \multicolumn{2}{|l|}{ Adequacy } \\
\hline & & & Median $(95 \%$ CI $)$ & $P$ & Median $(95 \%$ CI $)$ & $P$ & Median $(95 \% \mathrm{CI})$ & $P$ \\
\hline Infant & $110.2(35.8)$ & 0.519 & $1.4(0.5-2.3)$ & 0.700 & $8.6(6.4-10.8)$ & 0.065 & $90.0(87.7-92.3)$ & 0.069 \\
\hline Spring & $108.0(38.9)$ & & $2.9(0.0-6.9)$ & & $11.6(4.0-19.2)$ & & $85.5(77.2-93.8)$ & \\
\hline Summer & $113.2(37.1)$ & & $1.4(0.0-3.0)$ & & $11.4(7.1-15.7)$ & & $87.2(82.7-91.7)$ & \\
\hline Fall & $110.1(30.3)$ & & $1.4(0.0-3.0)$ & & $4.6(1.8-7.4)$ & & $94.0(90.8-97.2)$ & \\
\hline Winter & $106.8(34.6)$ & & $2.8(0.0-2.3)$ & & $9.1(4.2-14.0)$ & & $90.1(8.50-95.2)$ & \\
\hline Preschool child & $75.2(35.7)$ & 0.120 & $15.1(13.6-16.6)$ & 0.767 & $34.5(32.5-36.5)$ & 0.104 & $50.4(48.3-52.5)$ & 0.235 \\
\hline Spring & $71.9(39.4)$ & & $16.0(12.0-20.0)$ & & $35.7(30.5-40.9)$ & & $48.3(42.9-53.7)$ & \\
\hline Summer & $77.2(37.0)$ & & $14.4(11.9-16.9)$ & & $32.5(29.2-35.8)$ & & $53.1(49.6-56.6)$ & \\
\hline Fall & $76.4(33.1)$ & & $14.7(12.0-17.4)$ & & $35.4(31.8-39.0)$ & & $49.9(46.1-53.7)$ & \\
\hline Winter & $74.9(37.8)$ & & $16.1(12.9-19.3)$ & & $35.8(31.6-40.0)$ & & $48.1(43.8-52.4)$ & \\
\hline School child & $55.0(20.8)$ & 0.003 & $38.1(36.0-40.2)$ & 0.001 & $51.6(49.5-53.7)$ & 0.002 & $10.3(9.0-11.6)$ & 0.002 \\
\hline Spring $^{*}$ & $50.1(18.4)$ & & $53.6(47.0-60.2)$ & & $41.8(35.3-48.3)$ & & $4.6(1.9-7.3)$ & \\
\hline Summer $^{* *}$ & $56.9(21.5)$ & & $35.1(31.7-38.5)$ & & $52.2(48.7-55.7)$ & & $12.7(10.4-15.0)$ & \\
\hline Fall $^{*}$ & $58.4(21.1)$ & & $32.9(29.6-36.2)$ & & $55.9(52.4-59.4)$ & & $11.2(9.0-13.4)$ & \\
\hline Winter $^{* *}$ & $52.1(20.6)$ & & $48.8(43.1-54.5)$ & & $45.7(40.0-51.4)$ & & $5.5(2.9-8.1)$ & \\
\hline Adolescent & $46.2(19.0)$ & 0.001 & $54.6(51.3-57.9)$ & 0.001 & $38.9(35.6-42.2)$ & 0.002 & $6.5(4.8-8.2)$ & 0.002 \\
\hline Spring ${ }^{*}$ & $41.3(20.5)$ & & $73.6(65.4-81.8)$ & & $26.4(18.2-34.6)$ & & $0.0(0.0-0.0)$ & \\
\hline Summer ${ }^{* *}$ & $50.7(17.9)$ & & $51.4(46.2-56.6)$ & & $41.5(36.4-46.6)$ & & $7.1(4.4-9.8)$ & \\
\hline Fall $^{*}$ & $49.2(16.9)$ & & $44.0(38.1-49.9)$ & & $45.8(39.9-51.7)$ & & $10.2(6.6-13.8)$ & \\
\hline Winter $^{* *}$ & $40.2(19.7)$ & & $71.6(63.4-79.8)$ & & $26.7(18.6-34.8)$ & & $1.7(0.0-4.1)$ & \\
\hline
\end{tabular}

Data are expressed as median (quartile range (QR)) or median (95\% confidence interval (CI)). 25-OHD: 25-hydroxyvitamin D. ${ }^{*}$ Significantly different from next season but not significantly different from previous one; ${ }^{* *}$ Significantly different from previous season but not significantly different from next one

Table 4 Physical characteristics and vitamin D intakes of subjects

\begin{tabular}{|c|c|c|c|c|c|c|c|c|}
\hline \multirow{2}{*}{ Group } & \multicolumn{2}{|c|}{ Height $(\mathrm{cm})$} & \multicolumn{2}{|c|}{ Weight $(\mathrm{kg})$} & \multicolumn{3}{|c|}{ Outdoor activities $(\mathrm{h} / \mathrm{d})$} & \multirow{2}{*}{$\begin{array}{c}\text { Vitamin D } \\
\text { intake (IU/d) }\end{array}$} \\
\hline & Boy & Girl & Boy & Girl & SP/WI & SU/FA & $P$ & \\
\hline Infant & $70.1 \pm 4.4$ & $67.3 \pm 3.1$ & $8.8 \pm 2.1$ & $7.6 \pm 1.8$ & $0.96 \pm 0.18$ & $1.09 \pm 0.20$ & $<0.001$ & 437 (49) \\
\hline Preschool child & $100.7 \pm 4.0$ & $99.5 \pm 3.7$ & $15.9 \pm 1.9$ & $15.4 \pm 1.9$ & $1.83 \pm 0.24$ & $2.02 \pm 0.26$ & $<0.001$ & $134(28)$ \\
\hline School child & $138.1 \pm 5.6$ & $137.6 \pm 6.0$ & $32.6 \pm 5.7$ & $30.6 \pm 5.4$ & $0.94 \pm 0.14$ & $0.99 \pm 0.13$ & $<0.001$ & $123(43)$ \\
\hline Adolescent & $166.9 \pm 6.5$ & $158.6 \pm 5.6$ & $55.0 \pm 8.3$ & $48.4 \pm 6.4$ & $0.88 \pm 0.11$ & $0.96 \pm 0.12$ & $<0.001$ & $119(51)$ \\
\hline
\end{tabular}

Data are expressed as mean \pm standard deviation (SD) or median (quartile range (QR)). SP: spring; WI: winter; SU: summer; FA: fall

Medical Association (CMA) recommendation in 2008 that infants and toddlers from 2 weeks old to 2 years old receive 400 international units (IU) per day and another in 2009 that vitamin D-fortified food be fed to infants and toddlers aged from 0 to 3 years old. Almost all infants were supplemented with vitamin D, but taking supplements was a lot less popular for the older preschool children, and especially the school children and more especially the adolescents. If vitamin D supplements were excluded, there was no significant difference in median intake among these three age groups $(P=0.527)$. The intakes were derived mainly from sea fish (ca. 58\%), egg (ca. 22\%), and milk (ca. 15\%), and would be ca. 102 IU.

\section{Discussion}

Vitamin D deficiency and insufficiency are major global public health problems and must first be identified before they can be appropriately addressed. No national landscape of vitamin D status has been depicted in China, although the number of 25-OHD examinations in various populations, regions, and seasons has been escalating. Few investigations focused on infants, children, or adolescents, and yet their results were alarmingly below the threshold of $50 \mathrm{nmol} / \mathrm{L}$ (Arguelles et al., 2009; Foo et al., 2009; Strand et al., 2009; Zhang et al., 2014) and built up the same picture as in other parts of the world (Zhang 
et al., 2013). However, these previous researches were completed above latitude $30^{\circ} \mathrm{N}$, with sample sizes being generally very small.

Our investigation found that the dietary vitamin D intake for preschool children, school children, and adolescents in Wenzhou was mainly derived from sea fish and as the saying goes what we eat depends on what abounds in the place where we live, and that standing dishes full of sea fish all the year around provided substantial amounts of vitamin $\mathrm{D}$, so season had no effect on the dietary vitamin D intake. However, even such a diet was not enough to provide the daily allowance of $400 \mathrm{IU}$. The vitamin D intake exclusively from diet in these three age groups merely gave ca. $25 \%$ of the daily allowance, though it was much higher than those for adolescent girls in Beijing, China (Foo et al., 2009) and Greek preschool children (Nicolaidou et al., 2006), and on a par with that for British children aged 4-18 years (Absoud et al., 2011). Even with vitamin D supplementation included, it was much lower than the intake for American school children, whose prevalence of deficiency was $21 \%$ (Mansbach et al., 2009), compared to $38 \%$ in their Wenzhounese counterparts. Given that supplementation of vitamin D is less and less popular as children grew up, it was no wonder that vitamin D deficiency and insufficiency were prevalent and older age groups were involved in increasing risk in Wenzhou. Even so the mean and median 25-OHD levels among adolescents in Wenzhou were lower than those in 1006 European counterparts participating in a Healthy Lifestyle in Europe by Nutrition in Adolescence cross-sectional study (Gonzàlez-Gross et al., 2012; Moreno et al., 2014). Meanwhile, only $6.5 \%$ of adolescents in Wenzhou were vitamin D sufficient, compared to $18.9 \%$ in the same European study (Gonzàlez-Gross et al., 2012).

In sharp contrast, the vitamin D status in Wenzhounese infants, who were well supplemented in accordance with the CMA recommendations, excelled over that in advanced countries. For example, the prevalence of vitamin D deficiency was $1.4 \%$ and 9.7\% among Wenzhounese infants and American white infants (Bodnar et al., 2007), respectively. Therefore, we propose the CMA recommendations should be extended to older preschool children, school children, and adolescents, and even to all age groups.
More intriguingly, comparison of the physical characteristics and vitamin D intakes between preschool children and infants indicated that supplementation would be necessary for vitamin D status to be optimal even under the condition of outdoor activity time appropriate to the norm of $1-2 \mathrm{~h}$ per day recommended by the CMA. It meant that engagement in outdoor activities for 1-2 $\mathrm{h}$ per day did not suffice or the seemingly favorable geographical conditions did not guarantee endogenous synthesis of vitamin D as a result of skin exposure to solar ultraviolet B radiation. Further studies, however, will be needed to clarify this issue because investigation into actual solar ultraviolet B radiation and subjects' skin exposure to sunlight was not included in our questionnaire.

It would be conducive to displaying the vitamin D status on the southeastern coast of China to compare our study with an investigation conducted in Hangzhou (Zhu et al., 2012), not only because both Wenzhou and Hangzhou belong to Zhejiang Province and their people have similar lifestyle, but also because the two districts are distinct in many aspects. Hangzhou, the provincial capital, features a typical $\mathrm{Wu}$ culture, a branch of mainstream Chinese culture. Wenzhou, at the southernmost $2^{\circ}$ latitude apart, has more cultural and physical-anthropological traits originating from farther southern China.

According to the comparison (data not shown), the mean serum 25-OHD levels among infants and preschool children in Wenzhou were significantly higher than those in Hangzhou, whereas the levels among girl school children and among all or boy or girl adolescents in Wenzhou were significantly lower than those among their counterparts in Hangzhou.

Both Wenzhou and Hangzhou are affluent, and the Only Child policy in China makes parents eager to offer nutritious food to their babies. The data collection in Hangzhou took place between March 2008 and February 2011. We took samples between March 2014 and February 2015. During the intervening period of the studies, the awareness and concern that vitamin $\mathrm{D}$ deficiency and insufficiency are common and place children at high risk for chronic diseases had been growing in parents' minds thanks to the CMA recommendations for vitamin D supplementation. Meanwhile, vitamin D-fortified supplements had become easily accessible. The higher serum 25-OHD levels among infants and preschool children 
in Wenzhou than those in Hangzhou can therefore be a result of the rapid developments in China over the past decade.

Affluent though both districts are, the social infrastructure in newly developed Wenzhou still lags behind that in Hangzhou which has advanced for centuries and has been reputed as a paradise on Earth. As far as middle school students are concerned, admission to college from Wenzhou is more difficult than that from Hangzhou due to the relatively poorer quality of education. Students in Wenzhou consequently have to bear heavier burdens of classroom work in order to make up for this - getting into college is a long, frenzied, and competitive process in China. So they have less time playing outdoors and receiving solar radiation with a resulting poorer vitamin D status. This was supported by the statistical results from physical examination of college freshmen/ women in Zhejiang Province, with those from Hangzhou being the most healthy and those from Wenzhou the least (Zhejiang Provincial Department of Education, 2014). Thus, it is critical to infuse knowledge on the importance of vitamin $\mathrm{D}$ for healthy growth into the hearts of educators and educatees. As the saying of American philosopher and writer Ralph Waldo EMERSON goes, the first wealth is health!

Ancestors of the Wenzhounese mainly came from farther southern China. Although their genetic origins are diversified today and human skin color is affected by many substances, Wenzhounese are generally described as tan skinned compared to the northerners such as Hangzhounese just as dark skin is more often mentioned for the southerners (Eberhard, 1965). Fair skin is a very long-honed determinant of beauty and regarded as a sign of high socio-economic class in virtually mono-racial China. Girls in Wenzhou confess themselves beige pigmented, so they are more especially deeply indulged in light skin so that they avoid voluntary sun exposure. As they grow up and become fashion conscious, they hide beneath umbrellas, stay covered in clothes, or use sunscreens when going outside to keep the sun from 'disfiguring' their complexions. These behaviors may explain in part the finding that the mean serum 25-OHD levels among older girls in Wenzhou were significantly lower than those among their counterparts in Hangzhou. Only when adverse outcomes of vitamin D deficiency and insufficiency are recognized, will this neurosis and these induced behaviors harmful to healthy growth be changed.

Additionally, the significant seasonal differences in median serum 25-OHD level and prevalence of vitamin $\mathrm{D}$ deficiency and insufficiency were found in Wenzhou only between spring and summer and between fall and winter. By contrast, those in Hangzhou were also present between spring and winter. Based on theoretical calculation, Wenzhou and Hangzhou receive almost equal amounts of solar ultraviolet $B$ irradiances quarterly. In the past 50 years, however, there was average temperature difference of $4{ }^{\circ} \mathrm{C}$ in winter between Wenzhou $\left(8-16{ }^{\circ} \mathrm{C}\right)$ and Hangzhou $\left(4-12{ }^{\circ} \mathrm{C}\right)$ because of obstruction by mountains, while nearly zero temperature difference during other seasons $\left(9-16{ }^{\circ} \mathrm{C}\right.$ verse $7-15{ }^{\circ} \mathrm{C}$ in spring, $22-28{ }^{\circ} \mathrm{C}$ verse $21-29{ }^{\circ} \mathrm{C}$ in summer, and $21-29^{\circ} \mathrm{C}$ verse 20 $28^{\circ} \mathrm{C}$ in fall); furthermore, winter in Wenzhou lasted $25 \mathrm{~d}$ fewer than that in Hangzhou (Yang and Mao, 2008). Shorter duration and warmer temperature made winter in Wenzhou almost identical to its spring meteorologically, thus there was no seasonal difference between the two seasons.

\section{Conclusions}

This cross-sectional study showed that vitamin D deficiency and insufficiency were prevalent among infants, preschool children, school children, and adolescents in Wenzhou and became more severe as children grew up. There was no significant sex difference in mean serum 25-OHD level or prevalence of vitamin D deficiency and insufficiency in any age group, but there were significant seasonal differences in median level and prevalence among school children and adolescents, although the samples in our study were recruited from the health examinees rather than from the entire pediatric population. This is indeed a defect of the study but the big sample size is a remedy for representativeness. Lifestyle shaped by socio-economic environments affects vitamin D status. A diet full of sea fish provided a substantial amount of vitamin D all the year around, and yet it was not enough to give the daily allowance. Supplementation would be necessary even when outdoor activities for 1-2 $\mathrm{h}$ per day were guaranteed, though 
the natural conditions seem favorable to cutaneous synthesis of vitamin D. Consequently, the CMA recommendations for vitamin $\mathrm{D}$ supplementation should be extended to more age groups.

\section{Compliance with ethics guidelines}

Ling-li WANG, Hui-yan WANG, Huai-kai WEN, Hong-qun TAO, and Xiao-wei ZHAO declare that they have no conflict of interest.

All procedures followed were in accordance with the ethical standards of the human research ethics committee at the Second Hospital (also named the Yuying Children's Hospital) Affiliated to Wenzhou Medical University and with the Helsinki Declaration of 1975, as revised in 2008 (5). Informed consent was obtained from all subjects or their legal guardians for being included in the study.

\section{References}

Absoud, M., Cummins, C., Lim, M.J., et al., 2011. Prevalence and predictors of vitamin D insufficiency in children: a Great Britain population based study. PLoS ONE, 6(7): e22179.

http://dx.doi.org/10.1371/journal.pone.0022179

Arguelles, L.M., Langman, C.B., Ariza, A.J., et al., 2009. Heritability and environmental factors affecting vitamin D status in rural Chinese adolescent twins. J. Clin. Endocrinol. Metab., 94(9):3273-3281. http://dx.doi.org/10.1210/jc.2008-1532

Bischoff-Ferrari, H.A., Giovannucci, E., Willett, W.C., et al., 2006. Estimation of optimal serum concentrations of 25-hydroxyvitamin D for multiple health outcomes. Am. $J$ Clin. Nutr., 84(1):18-28.

Bodnar, L.M., Simhan, H.N., Powers, R.W., et al., 2007. High prevalence of vitamin D insufficiency in black and white pregnant women residing in the northern United States and their neonates. $J$. Nutr., 137(2):447-452.

Eberhard, W., 1965. Chinese regional stereotypes. Asian Surv., 5(12):596-608. http://dx.doi.org/10.2307/2642652

Foo, L.H., Zhang, Q., Zhu, K., et al., 2009. Relationship between vitamin D status, body composition and physical exercise of adolescent girls in Beijing. Osteoporosis Int., 20(3):417-425. http://dx.doi.org/10.1007/s00198-008-0667-2

Ganji, V., Zhang, X., Tangpricha, V., 2012. Serum 25hydroxyvitamin D concentrations and prevalence estimates of hypovitaminosis D in the U.S. population based on assay-adjusted data. J. Nutr., 142(3):498-507. http://dx.doi.org/10.3945/jn.111.151977

Gonzàlez-Gross, M., Valtueña, J., Breidenassel, C., et al., 2012. Vitamin D status among adolescents in Europe: the Healthy Lifestyle in Europe by Nutrition in Adolescence study. Br. J. Nutr., 107(5):755-764. http://dx.doi.org/10.1017/S0007114511003527

Holick, M.F., Binkley, N.C., Bischoff-Ferrari, H.A., et al., 2011. Evaluation, treatment, and prevention of vitamin D deficiency: an Endocrine Society Clinical Practice Guideline. J. Clin. Endocrinol. Metab., 96(7):1911-1930. http://dx.doi.org/10.1210/jc.2011-0385

Khor, G.L., Chee, W.S., Shariff, Z.M., et al., 2011. High prevalence of vitamin D insufficiency and its association with BMI-for-age among primary school children in Kuala Lumpur, Malaysia. BMC Public Health, 11(1):95. http://dx.doi.org/10.1186/1471-2458-11-95

Liu, A.L., Ma, G.S., Zhang, Q., et al., 2003. Reliability and validity of a 7-day physical activity questionnaire for elementary students. Chin. J. Epidemiol., 24(10):901-904 (in Chinese).

Lytle, L.A., Nichaman, M.Z., Obarzanek, E., et al., 1993. Validation of 24-hour recalls assisted by food records in third-grade children. J. Am. Diet. Assoc., 93(12):1431-1436. http://dx.doi.org/10.1016/0002-8223(93)92247-U

Mansbach, J.M., Ginde, A.A., Camargo, C.A.Jr., 2009. Serum 25-hydroxyvitamin D levels among US children aged 1 to 11 years: do children need more vitamin D? Pediatrics, 124(5):1404-1410. http://dx.doi.org/10.1542/peds.2008-2041

Moreno, L.A., Gottrand, F., Huybrechts, I., et al., 2014. Nutrition and lifestyle in European adolescents: the HELENA (Healthy Lifestyle in Europe by Nutrition in Adolescence) study. Adv. Nutr., 5(5):615S-623S. http://dx.doi.org/10.3945/an.113.005678

Nicolaidou, P., Kakourou, T., Papadopoulou, A., et al., 2006. Low vitamin D status in preschool children in Greece. Nutr. Res., 26(12):620-625. http://dx.doi.org/10.1016/j.nutres.2006.09.018

Palacios, C., Gonzalez, L., 2014. Is vitamin D deficiency a major global public health problem? J. Steroid Biochem. Mol. Biol., 144(A):138-145. http://dx.doi.org/10.1016/j.jsbmb.2013.11.003

Sallis, J.F., Buono, M.J., Roby, J.J., et al., 1993. Seven-day recall and other physical activity self-reports in children and adolescents. Med. Sci. Sport. Exer., 25(1):99-108. http://dx.doi.org/10.1249/00005768-199301000-00014

Schöttker, B., Ball, D., Gellert, C., et al., 2013. Serum 25-hydroxyvitamin D levels and overall mortality. A systematic review and meta-analysis of prospective cohort studies. Ageing Res. Rev., 12(2):708-718. http://dx.doi.org/10.1016/j.arr.2012.02.004

Strand, M.A., Perry, J., Zhao, J., et al., 2009. Severe vitamin D-deficiency and the health of north China children. Matern. Child Health J., 13(1):144-150. http://dx.doi.org/10.1007/s10995-007-0250-z

Wahl, D.A., Cooper, C., Ebeling, P.R., et al., 2012. A global representation of vitamin D status in healthy populations. Arch. Osteoporosis, 7(1):155-172. http://dx.doi.org/10.1007/s11657-012-0093-0

Yang, S.F., Mao, Y.D., 2008. Temperature variation of past 50 years and seasonal division in Zhejiang. Meteorol. Zhejiang, 29(4):1-6 (in Chinese).

Zhang, H.Q., Teng, J.H., Li, Y., et al., 2014. Vitamin D status and its association with adiposity and oxidative stress in schoolchildren. Nutrition, 30(9):1040-1044. 
http://dx.doi.org/10.1016/j.nut.2014.02.024

Zhang, W.G., Stoecklin, E., Eggersdorfer, M., 2013. A glimpse of vitamin D status in mainland China. Nutrition, 29(7-8):953-957.

http://dx.doi.org/10.1016/j.nut.2013.01.010

Zhejiang Provincial Department of Education, 2014. Bulletin on statistical results from physical examination of college freshmen/women in Zhejiang Province in 2013. Available from http://www.zjedu.gov.cn/news/142353458736472256.html [Accessed on Jan. 5, 2015] (in Chinese).

Zhu, Z.W., Zhan, J.Y., Shao, J., et al., 2012. High prevalence of vitamin D deficiency among children aged 1 month to 16 years in Hangzhou, China. BMC Public Health, 12(1): 126. http://dx.doi.org/10.1186/1471-2458-12-126

Zittermann, A., Gummert, J.F., 2010. Nonclassical vitamin D action. Nutrients, 2(4):408-425. http://dx.doi.org/10.3390/nu2040408

\section{中文概要}

题 目: 中国东南地区婴儿、儿童与少年的维生素 D 状态

目 的: 维生素 D 缺乏和不足是全球性的公共卫生问题, 欲妥善解决, 必首先了解之。
创新点：大部分亚太地区关于维生素 D 状态的信息奇缺, 本研究记录与分析了地处中国东南沿海的温州 的实际状况。

方 法: 2014 年 3 月至 2015 年 2 月之间, 总共检测了 5845 名年龄在 1 18 岁的贞儿、学前儿童、学龄儿童 与少年的血清 25-羟基维生素 D 水平。其均数分 别为 $(110.2 \pm 26.8) 、(77.5 \pm 25.7) 、(55.6 \pm 15.4)$ 与 $(47.2 \pm 13.9) \mathrm{nmol} / \mathrm{L}$ 。随着年龄增大, 发生维 生素 D 缺乏和不足的风险升高。学龄儿童与少年 的中位数与维生素 $\mathrm{D}$ 缺乏和不足发生率存在显 著的季节差异, 而所有年龄段的均数与发生率不 存在显著的性别差异。

结 论: 维生素 D 缺乏和不足普遍发生于温州的㚣儿、学 前儿童、学龄儿童与少年, 富含维生素 D 的饮食 与在有利于维生素 D 内源性合成的自然条件下 每天户外活动 1 2 小时并不能满足需求。温州婴 儿的维生素 D 状态优于美国婴儿, 是因为中国医 学会自 2008 年以来推荐 2 周至 2 岁的婴幼儿应 每天摄入 $400 \mathrm{IU}$ 维生素 D, 自 2009 年以来推荐 3 岁以下的婴幼儿应喂食维生素 D 强化食物, 因 此, 其推荐范围应当扩展至更多年龄段。因社会 经济环境形成的生活方式影响维生素 D 状态, 应 当广泛宣传关于维生素 $\mathrm{D}$ 对于健康生长至关重 要的知识。

关键词: 维生素 D; 缺乏; 儿童; 中国 